\title{
Evaluation of MODIS Products in the Great Australian Bight and Adjacent Coastal Waters
}

\author{
Ana Redondo Rodriguez ${ }^{1 *}$, Edward King'2, Mark Doubell1', Paul van Ruth ${ }^{1}$ \\ ${ }^{1}$ South Australian Research and Development Institute, West Beach, SA, Australia \\ ${ }^{2}$ CSIRO Oceans and Atmosphere Flagship CSIRO, Hobart, Australia \\ Email: ^Ana.RedondoRodriguez@sa.gov.au, Edward.King@csiro.au, Mark.Doubell@sa.gov.au, Paul.VanRuth@sa.gov.au
}

How to cite this paper: Rodriguez, A.R., King, E., Doubell, M. and van Ruth, P. (2018) Evaluation of MODIS Products in the Great Australian Bight and Adjacent Coastal Waters. Open Journal of Marine Science, 8, 431-449.

https://doi.org/10.4236/ojms.2018.84024

Received: September 25, 2018

Accepted: October 23, 2018

Published: October 26, 2018

Copyright $\odot 2018$ by authors and Scientific Research Publishing Inc. This work is licensed under the Creative Commons Attribution International License (CC BY 4.0).

http://creativecommons.org/licenses/by/4.0/

\begin{abstract}
Satellite remote sensing data can produce global environmental data and is easily accessible and widely used by the scientific and non-scientific community. However, to use satellite data, it is important to know its limitations and how it validates against in situ measurements for the different regions. Here, field measurements of chlorophyll-a concentration and euphotic depth within the Great Australian Bight, Gulf St Vincent and Spencer Gulf were used to validate ocean colour products derived from the Moderate Resolution Imaging Spectroradiometer (MODIS) onboard the Aqua satellite. The field data include in situ and in vivo chlorophyll-a concentration, which were compared against MODIS chlorophyll-a products derived from three algorithms (OC3M, Carder, and Garver-Siegel-Maritorena (GSM)), as well as euphotic depth measurements derived from photosynthetically active radiation (PAR) profiles, which were compared against two MODIS euphotic depth products (derived semi-analytically and from surface chlorophyll-a). The OC3M product performed well in open waters, with errors below the 35\% NASA accepted limit, but it overestimated chlorophyll-a values in shallow $(<50 \mathrm{~m})$ waters. The GSM product produced the lowest errors, but also showed a smaller dynamic range, while the Carder product produced higher errors than GSM and it also showed small dynamic range. The relationships between the MODIS and in situ euphotic depth were robust, with errors lower than $20 \%$. MODIS products showed weaker or no significant relationships to in situ measurements in the Eastern Great Australian Bight. This is thought to be due to the summertime subsurface upwelling pool that is characteristic of the area. Based on these results, the OC3M product provides the most reliable estimates of chlorophyll-a, and is recommended for further applications of MODIS imagery, if the limitations in shallow waters are taken into account. Alternatively, the GSM product could be a better option if the algorithm were locally adjusted. Changes in the sampling methodology to im-
\end{abstract}


prove the algorithms are discussed. Derived euphotic depth products can be used with confidence in applying MODIS products for monitoring water clarity, ecosystem health or primary productivity in the region.

\section{Keywords}

Great Australian Bight, MODIS, Remote Sensing, Ocean Color, Chlorophyll, Euphotic Depth

\section{Introduction}

Satellite systems are able to obtain global environmental data with great temporal coverage, and have provided important insights into marine ecosystem dynamics [1] [2] [3] [4]. Nowadays, satellite data is easily accessible from a number of institutions and is widely used not only by the scientific community but also by the general public. In some areas, ocean color-based chlorophyll-a concentration (chl) and sea surface temperature data are used operationally to indicate potential fishing and conservations zones [5] [6]. In addition, measurements of ocean color-based euphotic depth $\left(\mathrm{Z}_{\mathrm{eu}}\right)$ are essential for modeling primary productivity within the ocean [7]. However, satellite images must be calibrated with in situ measurements to ensure the quality of the data for different biomes [8] [9] [10] [11].

The processing of satellite ocean color data requires an atmospheric correction and the development of in-water bio-optical algorithms. Phytoplankton is the main optically active component of open marine waters, where changes in the optical properties are directly related to the chl. These waters are known as Case 1 waters [12] [13]. In coastal waters, colored dissolved organic matter (CDOM) and suspended inorganic matter, together with bottom reflectance, can also contribute significantly to changes in optical properties. In these cases, the different optically active constituents need to be characterized to accurately estimate the chl [14] [15]. These waters are known as Case 2 waters [16] [17].

Most operational satellite chl products are based on empirical relationships between chl and the reflectance ratio in several spectral bands. These products perform well in open waters [17] [18] [19] but may fail in coastal waters due to the presence of additional optically active substances [20] [21] [22]. Semi-analytical ocean color algorithms use a model to obtain characteristics of seawater optical components [23] [24] [25] but are more sensitive to errors in the atmospheric correction than empirically derived algorithms [10]. Similarly, the $Z_{\text {eu }}$ can be estimated empirically (derived from surface chl measurements) or by determining the vertical distribution of light from the optical properties [23] [26], and therefore is also influenced by water type and atmospheric corrections.

The Moderate Resolution Imaging Spectro-radiometer (MODIS) onboard the Aqua satellite is the moderate resolution mission from NASA. Currently, MODIS standard products (http://oceancolor.gsfc.nasa.gov/) include both em- 
pirical and semi-analytical global algorithms. Since general regressions are hard to establish for all water cases and locations, it is necessary to locally validate the different products against in situ measurements [8] [9] [10]. Owing to the remoteness of the Great Australia Bight (GAB) region in southern Australia (Figure 1), there has been a paucity of in situ data available for the assessment of satellite data. Previous validation studies in southern Australia have focused on the Spencer Gulf region; in particular, the southern area of the Gulf surrounding Port Lincoln, which supports the lucrative Southern Bluefin Tuna aquaculture industry [27] [28].

The purpose of this study is to evaluate the performance of satellite-based measurements of chl and $Z_{\text {eu }}$ using field-based measurements in the GAB, Gulf St Vincent and Spencer Gulf in order to determine whether the imagery is a reliable data source and to identify the most accurate products available for on-going monitoring and various research applications in the region. Satellite products evaluated here include: chl derived from the OC3M [18] [19], Carder [29] [30] and Garver-Siegel-Maritorena (GSM; [24]) algorithms, and $Z_{\text {eu }}$ derived from surface chl [31] and semi-analytically [23] from MODIS-Aqua.

\section{Data and Methods}

\subsection{Study Area}

The area of interest includes the GAB, Gulf St Vincent and Spencer Gulf, extending from $130^{\circ} \mathrm{S}$ to $139^{\circ} \mathrm{Sand} 31^{\circ} \mathrm{SE}$ to $37^{\circ} \mathrm{E}$ (Figure 1), and includes different ecological provinces. During winter, the $\mathrm{GAB}$ experiences downwelling, enhanced in the east through the outflow of cold, saline water formed in shallow regions of the GAB and gulfs. During summer, seasonal prevailing wind-driven upwelling events occur off the southern Eyre Peninsula and south-western Kangaroo

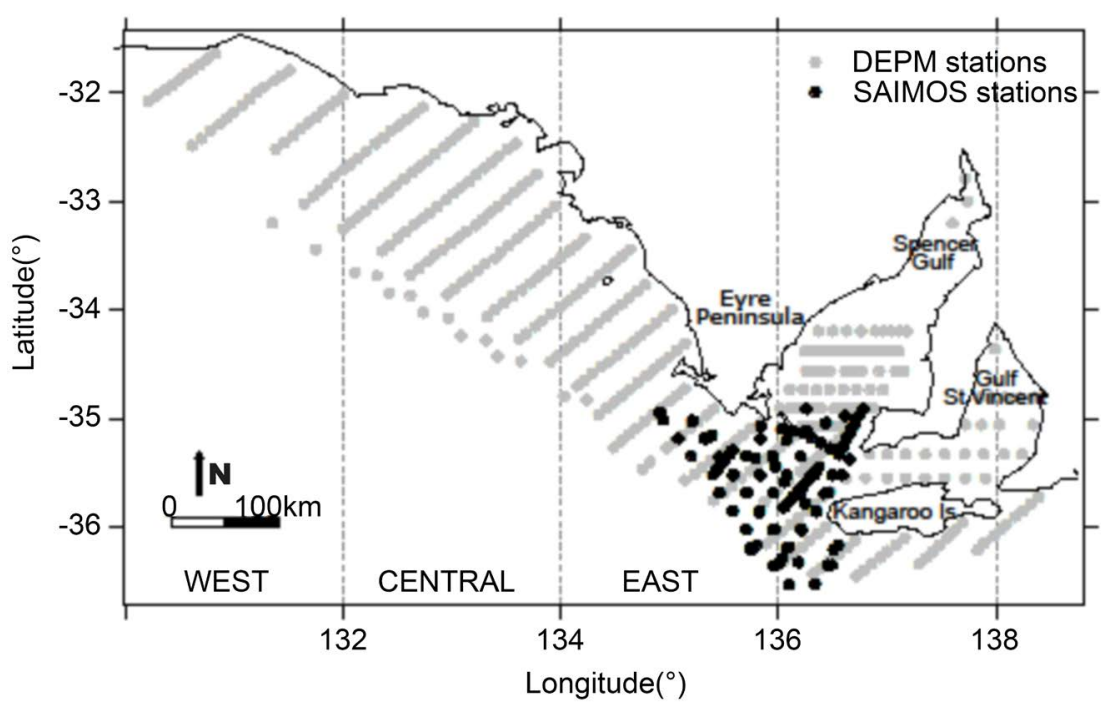

Figure 1. Study area and locations of the field stations visited during the sampling campaigns of the sardine daily egg production method surveys (grey circles) and the South Australian Integrated Marine Observing System (black circles). 
Island, while downwelling occurs all year round in the west and mid-GAB [11] [32] [33] [34] [35]. The summer upwelling is linked with a sub-surface chl maximum centered between Kangaroo Island and the southern tip of the Eyre Peninsula in the eastern GAB [11] [33] [35] [36]. The summer upwelling system presents ecological similarities to the productive eastern boundary upwelling systems in other regions of world, which are characterized by enhanced plankton production [11] [33] [35] [37].

Gulf St Vincent and Spencer Gulf are large inverse estuaries and experience seasonally limited exchange with the adjacent shelf waters [38]. Gulf St Vincent extends $\sim 170 \mathrm{~km}$, with a maximum width of $\sim 60 \mathrm{~km}$ and a typical depth of 35 $\mathrm{m}$, and is shallower than $15 \mathrm{~m}$ in the northernmost third of the Gulf. Spencer Gulf has a triangular shape and extends $\sim 320 \mathrm{~km}$ with a maximum width of 130 $\mathrm{km}$ and an average depth of $24 \mathrm{~m}$. During the austral summer, temperature fronts form across the mouth of Spencer Gulf reducing the exchange with upwelled waters on the shelf [39].

\subsection{Field Data}

\subsubsection{Chlorophyll- $a$}

We used two separate datasets of in situ chl obtained from water samples taken: 1) at $3 \mathrm{~m}$ depth during February and March from 2004 to 2006 as part of sardine daily egg production method (DEPM) surveys [40] (hereafter DEPM dataset) conducted by SARDI and 2) at either 10 or $15 \mathrm{~m}$ depth during several monthly trips from 2008 to 2014 as part of the South Australian Integrated Marine Observing System (SAIMOS). From each water sample, 1L (DEPM) or 4L (SAIMOS) samples were filtered through a Whatman GF/C filter and kept in the dark at $<5^{\circ} \mathrm{C}$ until returned to the laboratory. Samples were extracted in $90 \%$ methanol over 24 hours, with absorbance read at $750 \mathrm{~nm}$ (background) and $665 \mathrm{~nm}$ (chl) using a Hitachi U-2000 spectrophotometer with $1 \mathrm{~cm}$ pathlength. Chl were then calculated using the formulae of Talling and Driver [41]. The DEPM dataset included a total of 851 stations with in situ data, but only 145 matched with available MODIS data (see details below). Similarly, the SAIMOS dataset included a total of 118 stations, but only 10 matched with the MODIS data.

Coincident with the water sampling, in vivo chl measurements were taken from Conductivity-Temperature-Depth profiler (CTD) casts using either a Chelsea Aqua Tracka III fluorometer (Chelsea Technologies Group, Surrey, UK) or an ECO FL fluorometer (WetLabs, Rhode Island, US) attached to the CTD. From the fluorescence profiles we extracted the in vivo surface chl values at $5 \mathrm{~m}$ depth. In cases where two surface chlvalues (i.e. upcast and downcast) were available, we used an average of the two readings and excluded those values where the logarithmic differences were greater than 0.5 .

\subsubsection{Euphotic Depth}

During the DEPM surveys and SAIMOS project, profiles of photosynthetically active radiation (PAR) in the water column were recorded from CTD casts, us- 
ing either a Satlantic PAR-LOG-600 m PAR sensor (Satlantic LP, Halifax, Canada) or a Biospherical QSP-200L Log Quantum Scalar Irradiance Sensor (Biospherical Instruments Inc. San Diego, CA) attached to the CTD. From the PAR profiles we calculated the $Z_{\text {eu }}$, defined as the depth where PAR is reduced to $1 \%$ of the initial value at the surface. Firstly we calculated the PAR attenuation coefficient as the slope of the regression line of the log-transformed PAR with respect to depth, and then used the standard method to calculate the euphotic depth following the Beer-Lambert equation:

$$
\mathrm{Z}_{\mathrm{eu}}=1 / \mathrm{K}_{\mathrm{d}} \times \operatorname{Ln}(100 / 1)
$$

$$
\mathrm{K}_{\mathrm{d}}=\mathrm{PAR} \text { attenuation coefficient }
$$

Since the PAR profiles could be influenced by the boat shadow, we calculated the $Z_{\text {eu }}$ including only PAR values corresponding to depths greater than $5 \mathrm{~m}$. In cases where two PAR profiles (i.e. upcast and downcast) were available, we used an average of the values calculated from the two casts and excluded those were the differences were greater than $5 \mathrm{~m}$.

\subsection{MODIS Imagery}

MODIS Aqua level-2 daily imagery was obtained from the IMOS archive for Australia. These data were derived by processing raw 5-minute granules to level-1b and then level-2 using the NASA SeaDAS [42] processing package (v7.0.1). The level-2 processing step includes a correction for contribution of the atmosphere and results in data products with the native nadir resolution of approximately $1 \mathrm{~km}^{2}$. MODIS data were only extracted from the archive for days where the difference between the time of the data collection and the satellite overpass did not exceed 5 hours. We selected the following level-2 products: the chl derived from the OC3M, Carder and GSM algorithms, their corresponding level 2 flags, and the $Z_{\text {eu }}$ values.

The OC3M product is based on an empirical algorithm: a fourth degree polynomial regression between the pigment concentration and the spectral ratios of ocean reflectance [18] [19]. The GSM is a semi-analytical algorithm based on the bio-optical model inversion algorithm of Garver and Siegel [43], and optimized using a simulated annealing technique [24]. The Carder algorithm is also semi-empirical, but uses a more complex approach than the GSM, calculating the spectralab sorption properties of the sea water and splitting them into those associated with phytoplankton pigments and those associated with biological degradation products (e.g. CDOM). The absorption coefficient of phytoplankton chl is then adjusted in relation to the chl and the availability of light and nutrients [29] [30].

The $Z_{\text {eu }}$ is based on the semi-analytical algorithm of Lee et al. [44], computed from the absorption and backscattering coefficients. In addition, we used the surface chl values $(\mathrm{OC} 3 \mathrm{M})$ to compute the empirical $\mathrm{Z}_{\text {eu }}\left(\mathrm{Z}_{\mathrm{eu} \_} \mathrm{chl}\right)$ following the approach of Morel et al. [31] Equation (1).

$$
\log _{10}\left(\mathrm{Z}_{\text {eu_}} \mathrm{chl}\right)=1.524-0.436 x-0.0145 x^{2}+0.0186 x^{3}
$$




$$
x=\log _{10} \text { (chlorophyll-a concentration) }
$$

\subsection{Comparison between Field-Based and MODIS Data}

We compared the measurements obtained via the field-based sampling (both in situ and in vivo chl) with those derived from MODIS for each of the three chl products and the two $Z_{\mathrm{eu}}$ values following a modified general match-up exclusion protocol [45]. We edited the dataset using the Level 2 processing flags and masked out those pixels where any of the NASA operational Level 3 Ocean Color Processing flags (Table 1) were set. We identified and averaged the 9 pixels closest to the field-based measurement (within an array of 9 by 9 pixels centered on each of the locations). Only match-ups where at least 5 out of the 9 pixels contained valid data were included.

We calculated the relationship between the field-based value and the MODIS value via linear regression, and determined the goodness of fit through the coefficient of determination $\left(\mathrm{R}^{2}\right)$ and the Root Mean Square Error (RMSE). We tested the data for normality and log-transformed the values prior to the calculations when necessary.

\section{Results}

\subsection{Chlorophyll- $a$}

The relationship between the MODIS OC3M product and the DEPM in situ chl was weak (Table 2; Figure 2(a)), with an $\mathrm{R}^{2}$ value of 0.32 and a root mean

Table 1. Operational Ocean Color Processing masks.

Level-2 flags
Atmospheric correction failure
Pixel is over land
High sun glint
Observed radiance very high or saturated
High sensor view zenith angle
Stray-light contamination is likely
Probable cloud or ice contamination
Coccolithophores detected
High solar zenith
Very low water-leaving radiance (cloud shadow)
Derived product algorithm failure
Navigation quality is reduced
Aerosol iterations exceeded max
Derived product quality is reduced
Atmospheric correction is suspect
Bavigation



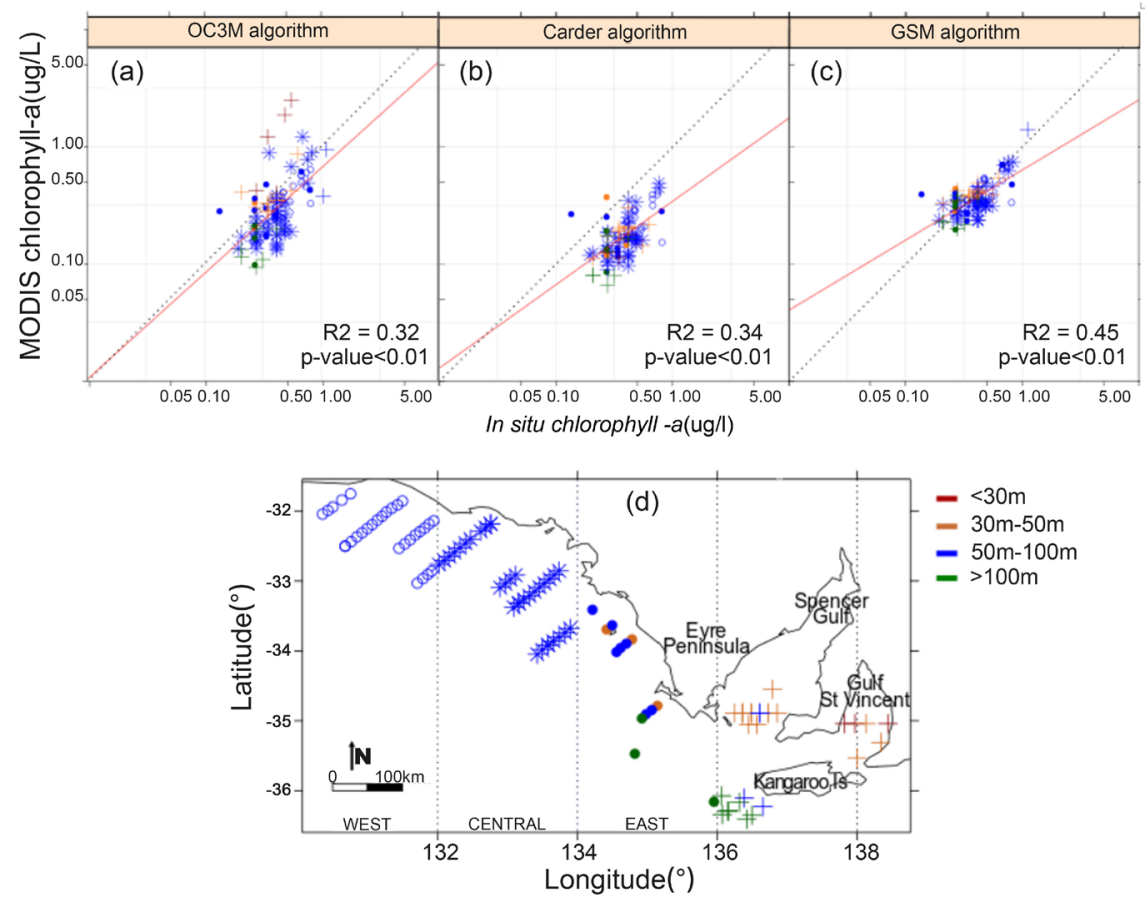

Figure 2. Relationships between MODIS (a) OC3M, (b) Carder and (c) GSM algorithms with in situ chlorophyll-a from the DEPM dataset. The red line corresponds to the fitted line and the black line represents a perfect fit (1:1). The symbols correspond to (d) the different sampling stations from the DEPM surveys that matched MODIS data. Colors represent different bathymetric depths (green $>100 \mathrm{~m}$, blue $=100-50 \mathrm{~m}$, orange $=50-$ $30 \mathrm{~m}$, red $\leq 30 \mathrm{~m})$.

Table 2. Regression statistics for MODIS and in situ chlorophyll-a data for the DEPM dataset.

\begin{tabular}{|c|c|c|c|c|c|c|c|}
\hline Algorithm & $\mathbf{n}$ & $\mathbf{R}^{2}$ & RMSE (ug/L) & RMSE (\%) & p-value & intercept & slope \\
\hline OC3M (All) & 121 & 0.32 & 0.29 & $81 \%$ & $<0.01$ & -0.42 & 0.90 \\
\hline $\mathrm{OC} 3 \mathrm{M}(>50 \mathrm{~m})$ & 98 & 0.46 & 0.15 & $48 \%$ & $<0.01$ & -0.51 & 0.92 \\
\hline OC3M (West GAB) & 30 & 0.66 & 0.07 & $21 \%$ & $<0.01$ & -0.44 & 1.01 \\
\hline OC3M (Central GAB) & 39 & 0.4 & 0.20 & $65 \%$ & $<0.01$ & -0.40 & 1.09 \\
\hline OC3M (East GAB) & 15 & 0.20 & 0.12 & $40 \%$ & 0.11 & -0.82 & 0.50 \\
\hline OC3M (KI) & 14 & 0.68 & 0.12 & $42 \%$ & $<0.01$ & -0.49 & 1.01 \\
\hline Carder (All) & 105 & 0.34 & 0.07 & $35 \%$ & $<0.01$ & -1.07 & 0.71 \\
\hline Carder $(>50 \mathrm{~m})$ & 84 & 0.37 & 0.07 & $35 \%$ & $<0.01$ & -1.05 & 0.75 \\
\hline Carder (West GAB) & 29 & 0.35 & 0.06 & $27 \%$ & $<0.01$ & -1.01 & 0.71 \\
\hline Carder (Central GAB) & 34 & 0.37 & 0.07 & $40 \%$ & $<0.01$ & -1.03 & 0.80 \\
\hline Carder (East GAB) & 10 & 0.01 & 0.07 & $38 \%$ & 0.90 & -7.74 & 0.04 \\
\hline Carder (KI) & 11 & 0.56 & 0.03 & $27 \%$ & $<0.01$ & -0.51 & 1.35 \\
\hline GSM (All) & 111 & 0.45 & 0.11 & $28 \%$ & $<0.01$ & -0.45 & 0.60 \\
\hline $\mathrm{GSM}(>50 \mathrm{~m})$ & 92 & 0.49 & 0.12 & $30 \%$ & $<0.01$ & -0.45 & 0.63 \\
\hline GSM (West GAB) & 29 & 0.34 & 0.09 & $21 \%$ & $<0.01$ & -0.50 & 0.55 \\
\hline
\end{tabular}


Continued

\begin{tabular}{cccccccc}
\hline GSM (Central GAB) & 38 & 0.52 & 0.08 & $24.2 \%$ & $<0.01$ & -0.48 & 0.66 \\
GSM (East GAB) & 13 & 0.17 & 0.11 & $32 \%$ & 0.16 & -0.75 & 0.31 \\
GSM (KI) & 12 & 0.84 & 0.07 & $17 \%$ & $<0.01$ & 0.12 & 1.09 \\
\hline
\end{tabular}

(n: number of samples; $\mathbf{R}^{2}$ : coefficient of determination; RMSE: Root mean square error).

square error (RMSE) of $81 \%$. Bottom reflectance and the presence of different optical substances in shallow near-shore and gulf waters, may play a role in this poor relationships, so we repeated the regression excluding locations where the water depth is $<50 \mathrm{~m}$ (which excludes the gulfs). In doing so, the relationships improved considerably $\left(\mathrm{R}^{2}=0.46\right)$, although the RMSE remained over the $35 \%$ linear accuracy goal set by NASA for chlorophyll retrievals [46] [47]. The correlation, however, varied spatially, being highest off $\mathrm{KI}$ and in the western GAB (Figure 2(d)), intermediate in the central GAB, and non-significant in the eastern GAB (Table 2).

The Carder and GSM products (Figure 2(b) and Figure 2(c)), designed for Case 2 waters, were not affected by the exclusion of shallow waters from the analysis (Table 2) and their RMSE were within the 35\% accepted NASA limit. Both products still showed squared correlation coefficients to be lower than 0.5 . As per the OC $3 \mathrm{M}$, both products showed a better relationship with in situ data in the west $\mathrm{GAB}\left(\mathrm{R}^{2} \sim 0.35\right)$ and also around Kangaroo Island $\left(\mathrm{R}^{2}>0.5\right)$ and no significant relationships in the east GAB ( $\mathrm{p}$-value $=0.16$ ).

The method used to calculate the in situ chl from the water samples was not able to resolve small variations in concentrations, leading to an apparent quantisation, or binning, of the field-based values (Figure 2). The limited precision in the methodology may result in apparent errors in MODIS when the datasets are compared. To account for these apparent errors, we repeated the analysis with a second field-based dataset based on in vivo chl values measured using a CTD fitted with a fluorometer (CTD-F) during DEPM surveys [40]. Chl data derived from fluorometers should be used with caution, since changes in the phytoplankton population, environmental state, physiological state, quenching, instruments and calibrations may all lead to erroneous or biased measurements [48]-[53]. In order to minimize the bias within and between instruments we considered each instrument calibrated within a period of a year as a separate dataset.

The relationships between the MODIS and in vivo chl data are generally stronger than with the in situ data, with $\mathrm{R}^{2}$ values $>0.5$ for all regressions performed, except for the Carder product (Table 3, Figure3). However, most of the MODIS data overestimated the in vivo chl values. Such bias is likely due to the methodology used to measure in vivo chl rather than an overestimation from MODIS, since fluorometers tend to underestimate the chl present in sea water [53]. For 2004, the OC3M achieved the best relationship in terms of $R^{2}$ values $\left(R^{2}\right.$ $=0.83$ ), however, it also had the greatest RMSE (36\%). In contrast, for 2005, 

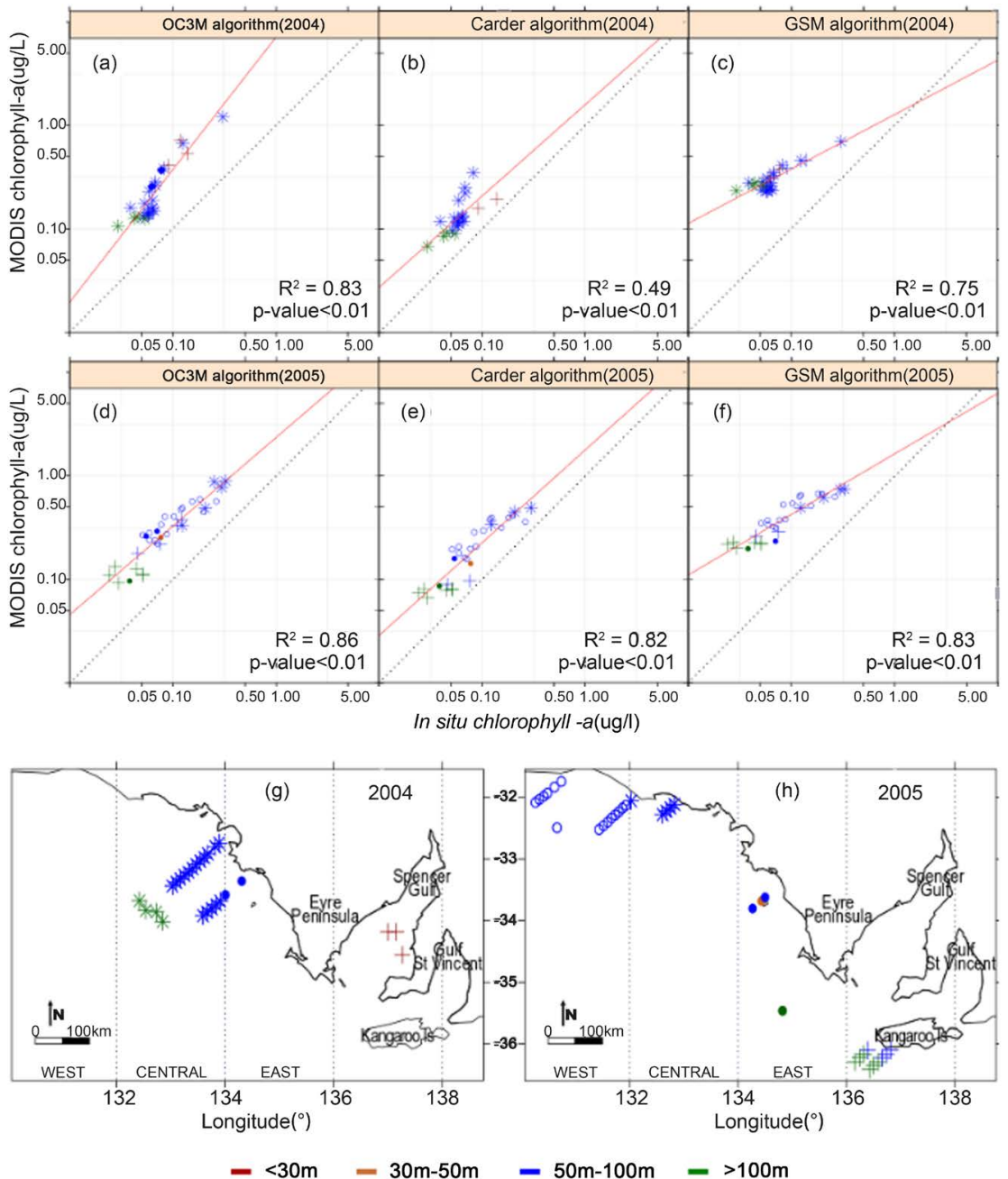

Figure 3. Relationships between MODIS (a) OC3M, (b) CARDER and (c) GSM algorithms with the -a dataset during 2004 and between MODIS (d) OC3M, (e) CARDER and (f) GSM algorithms with the in vivo chlorophyll-a dataset during 2005. The red line corresponds to the fitted line and the black line represents a perfect fit (1:1). The symbols correspond to the different sampling stations from the DEPM surveys that matched MODIS data during (g) 2004 and (h) 2005. Colors represent different bathymetric depths (green $>100 \mathrm{~m}$, blue $=100-50 \mathrm{~m}$, orange $=50-30 \mathrm{~m}$, red $\leq 30 \mathrm{~m})$.

Table 3. Regression statistics for MODIS and in vivo chlorophyll-a data for the DEPM dataset.

\begin{tabular}{cccccccc}
\hline Algorithm & $\mathbf{n}$ & $\mathbf{R}^{2}$ & RMSE (ug/L) & RMSE (\%) & p-value & Intercept & Slope \\
\hline & & \multicolumn{7}{c}{2004} \\
OC3M (All) & 26 & 0.83 & 0.1 & $36 \%$ & $<0.01$ & 1.97 & 1.28 \\
OC3M (>50 m) & 23 & 0.83 & 0.07 & $29 \%$ & $<0.01$ & 1.75 & 1.21 \\
Carder (All) & 21 & 0.49 & 0.05 & $34 \%$ & $<0.01$ & 0.46 & 0.88 \\
Carder (>50 m) & 19 & 0.58 & 0.05 & $33 \%$ & $<0.01$ & 1.72 & 1.31 \\
GSM (All) & 25 & 0.75 & 0.04 & $12 \%$ & $<0.01$ & 0.24 & 0.53 \\
GSM (>50 m) & 23 & 0.72 & 0.04 & $13 \%$ & $<0.01$ & 0.20 & 0.51 \\
\hline
\end{tabular}




\section{Continued}

\begin{tabular}{cccccccc}
\hline & \multicolumn{7}{c}{2005} \\
OC3M (All) & 34 & 0.86 & 0.08 & $21 \%$ & $<0.01$ & 0.86 & 0.86 \\
OC3M (West GAB) & 15 & 0.76 & 0.07 & $17 \%$ & $<0.01$ & 0.42 & 0.62 \\
Carder (All) & 29 & 0.82 & 0.06 & $28 \%$ & $<0.01$ & 0.58 & 0.89 \\
Carder (West GAB) & 15 & 0.72 & 0.05 & $19 \%$ & $<0.01$ & 0.07 & 0.06 \\
GSM (All) & 29 & 0.83 & 0.08 & $18 \%$ & $<0.01$ & 0.50 & 0.59 \\
GSM (West GAB) & 15 & 0.73 & 0.08 & $16 \%$ & $<0.01$ & 0.42 & 0.51 \\
\hline
\end{tabular}

(n: number of samples; $\mathbf{R}^{2}$ : coefficient of determination; RMSE: Root mean square error).

OC3M performed the best on both criteria, with an $\mathrm{R}^{2}$ and RMSE of 0.86 and $21 \%$, respectively. Differences between the performances of the algorithms may be related to the location of the sampling stations within the years (Figure $3 \&$ Figure 4). During 2004, a number of stations were located in shallow waters within the gulfs, while in 2005 all the stations were located in open waters, with more stations in the west $\mathrm{GAB}$ and $\mathrm{KI}$ areas.

We repeated the regressions for 2004 excluding locations with depth $<50 \mathrm{~m}$ (which excludes the gulfs). This improved the OC3M relationship (RMSE = $29 \%$ ), while the results for the other two algorithms remained the same. As before, the RMSEs for all the algorithms were lower for the west GAB region.

The relationship between the MODIS and the SAIMOS in situ chl (Table 4) was moderate, with an $\mathrm{R}^{2}$ value $>0.5$ for all products. The number of data points used for the regressions however is very small, and the results are not significant at the $99 \%$ level $(\mathrm{n}<10, \mathrm{p}=0.02)$, hence the results should be used with caution. Regressions between MODIS and the in vivo data from SAIMOS were non-significant and involve a low number of data points $(\mathrm{n}<10$, $\mathrm{p}$-value $>0.05$; not shown).

\subsection{Euphotic Depth}

The relationships between the MODIS and the in situ $\mathrm{Z}_{\mathrm{eu}}$ from the DEPM dataset were generally very good (Table 5, Figure 4 (a) and Figure 4(b)). The $Z_{\text {eu }}$ estimated from the surface chl values $\left(\mathrm{R}^{2}=0.73, \mathrm{RMSE}=11 \%\right)$ were better than those derived by the Lee (2007) semi-analytical algorithm $\left(\mathrm{R}^{2}=0.69, \mathrm{RMSE}=\right.$ $18 \%$ ), however, the former tended to underestimate the $Z_{\text {eu }}$ of the clearest waters. There were no substantial differences in the performance of both algorithms when disregarding the shallow waters (depth $<50 \mathrm{~m}$ ). As with the chl values, the correlations between the satellite and in situ datavaried between the different areas of the GAB and the best matches occurred within the west GAB, where the RMSE from both algorithms fell below $10 \%$.

In contrast, the relationships between MODIS and the SAIMOS in situ $\mathrm{Z}_{\text {eu }}$ (Figure 4(c) and Figure 4(d)) were less robust and the best matches occurred for the chl derived $Z_{\mathrm{eu}}$ within the east GAB. Again, there were a smaller number 

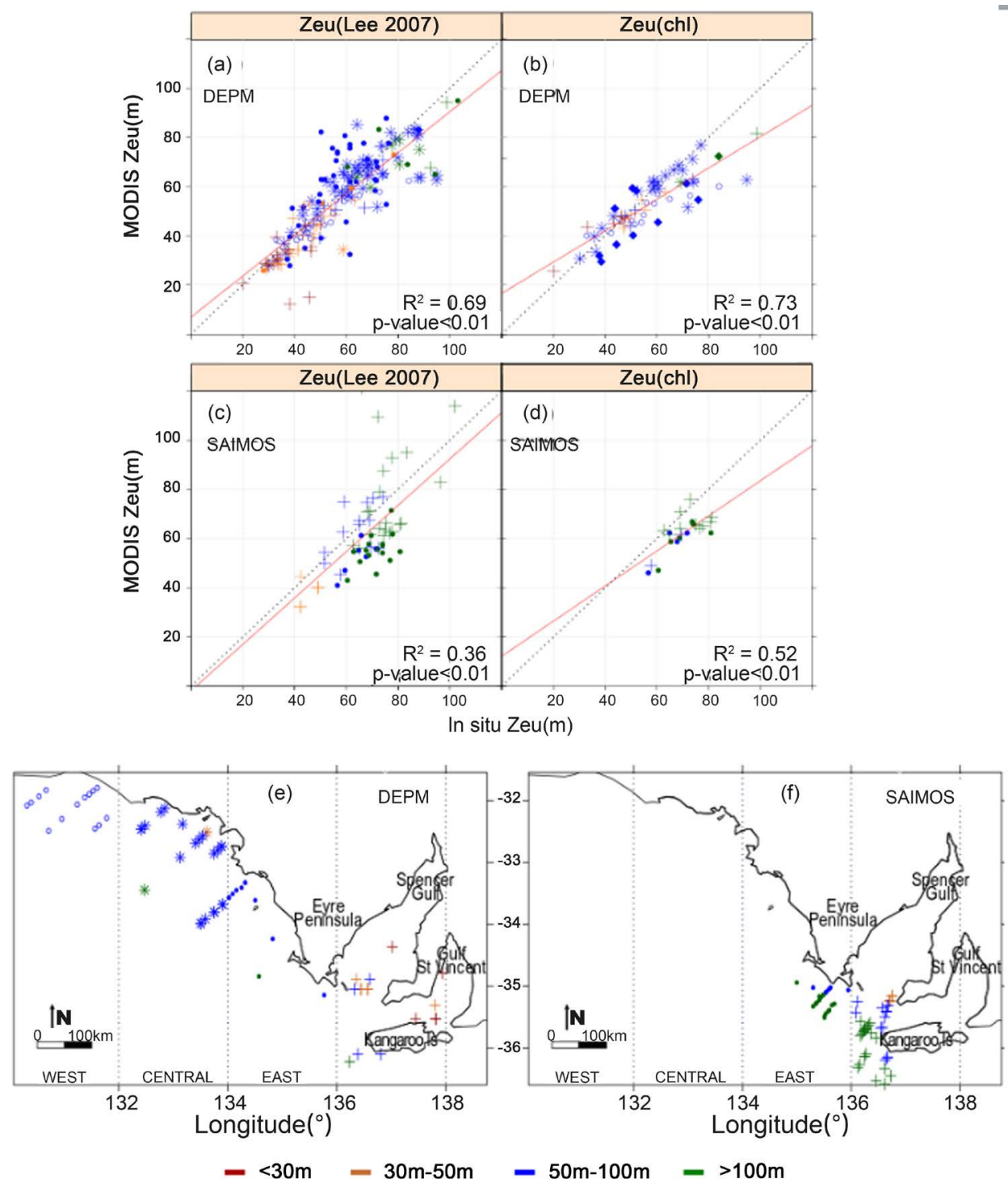

Figure 4. Relationships between MODIS euphotic depth based on (a) Lee (2007) algorithm and (b) surface chlorophyll-a concentration with the field-based euphotic depth data from the DEPM project and between MODIS euphotic depth based on (c) Lee (2007) algorithm and (d) surface chlorophyll-a concentrations with the field-based euphotic depth data from the SAIMOS project. The red line corresponds to the fitted line and the black line represents a perfect fit (1:1). The symbols correspond to the different sampling stations from the (e) DEPM and (f) SAIMOS surveys that matched MODIS data. Colors represent different bathymetric depths (green $>100 \mathrm{~m}$, blue $=100-50 \mathrm{~m}$, orange $=50-30 \mathrm{~m}$, red $\leq 30 \mathrm{~m}$ ).

Table 4. Regression statistics for MODIS and in situ chlorophyll-a data for the SAIMOS dataset.

\begin{tabular}{cccccccc}
\hline Algorithm & $\mathbf{n}$ & $\mathbf{R}^{2}$ & RMSE (ug/L) & RMSE (\%) & p-value & Intercept & Slope \\
\hline OC3M & 9 & 0.58 & 0.15 & $34 \%$ & 0.02 & -0.65 & 0.85 \\
Carder & 9 & 0.58 & 0.20 & $44 \%$ & 0.02 & -0.55 & 1.2 \\
GSM & 8 & 0.62 & 0.11 & $22 \%$ & 0.02 & -0.46 & 0.65 \\
\hline
\end{tabular}

( $\mathrm{n}$ : number of samples; $\mathbf{R}^{2}$ : coefficient of determination; RMSE: Root mean square error). 
Table 5. Regression statistics for MODIS and in situ euphotic depth data.

\begin{tabular}{|c|c|c|c|c|c|c|c|}
\hline Algorithm & $\mathbf{n}$ & $\mathbf{R}^{2}$ & RMSE (m) & RMSE (\%) & $\mathrm{p}$-value & Intercept & Slope \\
\hline \multicolumn{8}{|c|}{ DEPM } \\
\hline Lee (All) & 175 & 0.69 & 9.67 & $18 \%$ & $<0.01$ & 6.8 & 0.84 \\
\hline Lee $(<50 \mathrm{~m})$ & 131 & 0.57 & 9.66 & $16 \%$ & $<0.01$ & 16.1 & 0.71 \\
\hline Lee (West GAB) & 20 & 0.89 & 2.73 & $6 \%$ & $<0.01$ & 14.99 & 0.62 \\
\hline Lee (Central GAB) & 59 & 0.64 & 7.67 & $12 \%$ & $<0.01$ & 19.43 & 0.67 \\
\hline Lee (East GAB) & 42 & 0.40 & 12.5 & $20 \%$ & $<0.01$ & 21.5 & 0.68 \\
\hline Lee (KI) & 10 & 0.80 & 7.39 & $12 \%$ & $<0.01$ & 6.02 & 0.81 \\
\hline Chl (All) & 64 & 0.73 & 6.00 & $11 \%$ & $<0.01$ & 16.5 & 0.64 \\
\hline $\mathrm{Chl}(<50 \mathrm{~m})$ & 51 & 0.70 & 6.47 & $12 \%$ & $<0.01$ & 16.1 & 0.65 \\
\hline Chl (West GAB) & 14 & 0.85 & 2.59 & $5 \%$ & $<0.01$ & 23.3 & 0.48 \\
\hline Chl (Central GAB) & 21 & 0.69 & 6.66 & $11.5 \%$ & $<0.01$ & 19.3 & 0.63 \\
\hline Chl (East GAB) & 11 & 0.62 & 8.01 & $16 \%$ & $<0.01$ & 11.1 & 0.68 \\
\hline \multirow[t]{2}{*}{$\mathrm{Chl}(\mathrm{KI})$} & 5 & 0.98 & 2.03 & $3.54 \%$ & $<0.01$ & 12.96 & 0.69 \\
\hline & \multicolumn{4}{|c|}{ SAIMOS } & & & \\
\hline Lee (All) & 61 & 0.36 & 14 & $22 \%$ & $<0.01$ & -1.86 & 0.94 \\
\hline Lee (East GAB) & 22 & 0.35 & 5.28 & $10 \%$ & $<0.01$ & 11.12 & 0.62 \\
\hline Lee (KI) & 34 & 0.25 & 15.08 & $21 \%$ & $<0.01$ & 11.48 & 0.85 \\
\hline Chl (All) & 22 & 0.52 & 4.83 & $8 \%$ & $<0.01$ & 12.16 & 0.71 \\
\hline Chl (East GAB) & 10 & 0.67 & 3.83 & $6 \%$ & $<0.01$ & 2.79 & 0.82 \\
\hline Chl (KI) & 12 & 0.38 & 4.81 & $7 \%$ & 0.03 & 25.8 & 0.54 \\
\hline
\end{tabular}

(n: number of samples; $\mathbf{R}^{2}$ : coefficient of determination; RMSE: Root mean square error).

of data points for this comparison, and the data collected by SAIMOS was not only from the upwelling season (February and March) but across seasons.

\section{Discussion}

To guarantee the quality and consistency of remote sensing data, they must be validated against field-based observations [8] [9] [10] [11]. Validation exercises have been performed around the world, resulting in improved regional algorithms [4] [9] [54] [55]. We analyzed the performance of various MODIS chl and $Z_{\text {eu }}$ products, using historical field-based datasets collected between 2003 and 2014 in the GAB and gulf regions of southern Australia. To our knowledge, this is the first study presenting a validation of remote sensing $Z_{\text {eu }}$ and chl imagery in the GAB area using in situ and in vivo measurements. Previous validation exercises have been carried out in Spencer Gulf in the vicinity of the Port Lincoln aquaculture Tuna Farming Zone [27] [28] for chl and SST, and their findings are consistent with the results shown here for gulf waters.

In general, the OC3M chl product performed better in open waters, while it 
tended to overestimate chl in shallow (depth $<50 \mathrm{~m}$ ) waters. The OC3M was designed primarily for case 1 waters and, hence, the overall poor performance in the gulfs and shallow waters (which are also generally coastal) is not surprising. Removing data from shallow waters improved the accuracies, with RMSE errors falling below the accepted NASA 35\% error limit [46] [47]. In contrast, the semi-analytical products based on the model of Carder et al. [29] and GSM, which were designed to have an improved performance in optically complex waters, produced consistent results irrespective of whether shallow waters were included. The GSM semi-analytical algorithm produced the lowest errors, although it produced an average slope of $\sim 0.6$, overestimating low of chl and vice versa and it presented a smaller dynamic range.

Based on these results, the OC $3 \mathrm{M}$ chl product provides the most reliable estimates of chl and is recommended for further applications of MODIS imagery in the region, if the limitations in shallow waters are taken into account. Alternatively, the GSM algorithm could be a better option if the algorithm were locally adjusted.

The correct evaluation of the different satellite products requires accurate field-based measurements; however the methodology used to infer in situ chl was subject to errors (due to limited precision and bias inherent to the methodology). The use of a high-performance liquid chromatography (HPLC) method (currently used by the SAIMOS project) will improve the accuracy of the in situ chl data, while developing strict calibration and quality control protocols for the in vivo data will provide a more consistent dataset [56].

Optical variability across the study environment affected the performance of the three chl products examined here, and further improvements would be necessary before their utilization for an operational monitoring of the GAB shallow waters. All products showed better relationships with the DEPM in situ data within the west GAB and failed to give significant results in the east GAB. Such differences may be due to the fact that the east GAB is characterized by a subsurface chl maximum during the upwelling season (Jan/Feb/Mar; [11] [33] [35] [36] [57]). Field measurements of chl are taken at a discrete location in the water column, while the satellite observations are a weighted mean over the light-penetrating depth of the water column. Therefore, changes in the vertical profile may not be properly recorded by discrete sampling while changes on the vertical profile for deeper (subsurface) areas will not be properly estimate by the satellite.

To generate a locally improved algorithm, sampling efforts should be directed to collecting a comprehensive bio-optical dataset, including in situ remote sensing reflectance and spectral absorption coefficients, that would help to determine whether the performance of the products is related to the effect of the spectral ratios considered or to the determination of the spectral contributions of different seawater constituents [8] [9] [58].

The relationships between the MODIS and in situ $\mathrm{Z}_{\mathrm{eu}}$ were robust, with RMSE 
lower than $20 \%$. For the $G A B$, the $Z_{\text {eu }}$ values derived from the surface chl values were better than those derived semi-analytically in terms of RMSE, although they had lower slopes. As with the chl data, the relationships with the in situ data from the sardine DEPM surveys (collected during the upwelling season) in the east GAB were notably weaker. The results of the MODIS $Z_{\text {eu }}$ derived from surface chl profiles were robust even in shallow water. The $Z_{\mathrm{eu}}$ does not depend on a specific absorption coefficient and, compared to chl, it is much easier and more accurate to determine in the field and less subject to errors due to limited precision and bias inherent to the methodology, thus $Z_{\text {eu }}$ produced very small errors compared with the chl data. Our results indicate that derived $Z_{\text {eu }}$ could be used with confidence in applying MODIS products for monitoring water clarity, ecosystem health or primary productivity in the region.

\section{Conclusion}

We have evaluated the performance of the satellite-based measurements of chl and $Z_{\text {eu }}$ against field-based measurements within the GAB and Gulf St Vincent and Spencer Gulf. The performance of the OC3M chl product, although reliable within open waters, is poor within the gulfs, while the GSM produces the least errors but has less dynamic range. The chl algorithms could be re-evaluated and improved to be used with confidence in the GAB area if a comprehensive bio-optical dataset was to be collected. The $Z_{\text {eu }}$ showed good performance and it is considered a reliable dataset to be used for future applications within the GAB.

\section{Acknowledgements}

This study was conducted as part of the Great Australian Bight Research Program, a collaboration between BP, Commonwealth Scientific and Industrial Research Organization (CSIRO), SARDI, the University of Adelaide, and Flinders University. The Program aims to provide a whole of system understanding of the environmental, economic and social values of the region, providing an information source for all to use.

\section{Supported}

Ana Redondo Rodriguez, Mark Doubell and Paul van Ruth are supported by the Great Australian Bight Research Program, a collaboration between BP, CSIRO, the South Australian Research and Development Institute (SARDI), the University of Adelaide, and Flinders University. Data were sourced from the Integrated Marine Observing System (IMOS). IMOS is supported by the Australian Government through the National Collaborative Research Infrastructure Strategy and the Super Science Initiative.

\section{Conflicts of Interest}

The authors declare no conflicts of interest regarding the publication of this paper. 


\section{References}

[1] Bousquet, P., Ciais, P., Miller, J.B., Dlugokencky, E.J., Hauglustaine, D.A., Prigent, C., Van der Werf, G.R., Peylin, P., Brunke, E.G., Carouge, C., Langenfelds, R.L., Lathiere, J., Papa, F., Ramonet, M., Schmidt, M., Steele, L.P., Tyler, S.C. and White, J. (2006) Contribution of Anthropogenic and Natural Sources to Atmospheric Methane Variability. Nature, 443, 439-443. https://doi.org/10.1038/nature05132

[2] Mohr, J.J. and Forsberg, R. (2002) Remote Sensing: Searching for New Islands in Sea Ice-Coastlines Concealed in Polar Seas Are Now More Accessible to Cartography. Journal of Geophysical Resesarch C: Oceans, 106, 7163-7180.

[3] Bosc, E., Bricaud, A. and Antoine, D. (2004) Seasonal and Interannual Variability in Algal Biomass and Primary Production in the Mediterranean Sea, as Derived from 4 Years of SeaWiFS Observations. Global Biogeochemical Cycles, 18. https://doi.org/10.1029/2003GB002034

[4] Krishna, K.M. and Rao, S.R. (2008) Seasonal and Interannual Variability of Sea Surface Chlorophyll a Concentration in the Arabian Sea. Journal of Applied Remote Sensing, 2, 023501. https://doi.org/10.1117/1.2837118

[5] Petit, M., Gaspar, P., Lahet, F., Demagistri, L., Desruisseaux, M., Boschet, C., Rey-Valette, H. and Lebras, J.-Y. (2003), SeAGeRH Project: Toward a Service of Fisheries Management Assisted by Satellites. Toulouse (FRA).

[6] Royer, F., Fromentin, J.M. and Gaspar, P. (2004) Association between Bluefin Tuna Schools and Oceanic Features in the Western Mediterranean. Marine Ecology Progress Series, 269, 249-263. https://doi.org/10.3354/meps269249

[7] Behrenfeld, M.J. and Falkowski, P.G. (1997) A Consumer's Guide to Phytoplankton Primary Productivity Models. Limnology and Oceanography, 42, 1479-1491. https://doi.org/10.4319/lo.1997.42.7.1479

[8] Tilstone, G.H., Lotliker, A.A., Miller, P.I., Ashraf, R.M., Kumar, T.S., Suresh, T., Ragavan, B.R. and Menon, H.B. (2013) Assessment of MODIS-Aqua Chlorophyll-a Algorithms in Coastal and Shelf Waters of the Eastern Arabian Sea. Continental Shelf Research, 65, 14-26. https://doi.org/10.1016/j.csr.2013.06.003

[9] Lapucci, C., Rella, M.A., Brandini, C., Ganzin, N., Gozzini, B., Maselli, F., Massi, L., Nuccio, C., Ortolani, A. and Trees, C. (2012) Evaluation of Empirical and Semi-Analytical Chlorophyll Algorithms in the Ligurian and North Tyrrhenian Seas. Journal of Applied Remote Sensing, 6, 063565. https://doi.org/10.1117/1.JRS.6.063565

[10] Salyuk, P., Bukin, O., Alexanin, A., Pavlov, A., Mayor, A., Shmirko, K., Akmaykin, D. and Krikun, V. (2010) Optical Properties of Peter the Great Bay Waters Compared with Satellite Ocean Colour Data. International Journal of Remote Sensing, 31, 4651-4664. https://doi.org/10.1080/01431161.2010.485219

[11] van Ruth, P.D., Ganf, G.G. and Ward, T.M. (2010) Hot-Spots of Primary Productivity: An Alternative Interpretation to Conventional Upwelling Models. Estuarine Coastal and Shelf Science, 90, 142-158. https://doi.org/10.1016/j.ecss.2010.08.009

[12] Gordon, H.R. and Morel, A.Y. (1983) Remote Assessment of Ocean Color for Interpretation of Satellite Visible Imagery: A Review. Springer-Verlag, New York. https://doi.org/10.1029/LN004

[13] Morel, A. and Prieur, L. (1977) Analysis of Variations in Ocean Color. Limnology and Oceanography, 22, 709-722. https://doi.org/10.4319/lo.1977.22.4.0709

[14] Darecki, M. and Stramski, D. (2004) An Evaluation of MODIS and SeaWiFS Bio-Optical Algorithms in the Baltic Sea. Remote sensing of Environment, 89, 
326-350. https://doi.org/10.1016/j.rse.2003.10.012

[15] Cannizzaro, J.P. and Carder, K.L. (2006) Estimating Chlorophyll a Concentrations from Remote-Sensing Reflectance in Optically Shallow Waters. Remote Sensing of Environment, 101, 13-24. https://doi.org/10.1016/j.rse.2005.12.002

[16] Bukata, R.P., Jerome, J.H., Kondratyev, A.S. and Pozdnyakov, D.V. (1995) Optical Properties and Remote Sensing of Inland and Coastal Waters. CRC Press, Boca Raton.

[17] Sathyendranath, S., Cota, G., Stuart, V., Maass, H. and Platt, T. (2001) Remote Sensing of Phytoplankton Pigments: A Comparison of Empirical and Theoretical Approaches. International Journal of Remote Sensing, 22, 249-273. https://doi.org/10.1080/014311601449925

[18] O’Reilly, J.E., Maritorena, S., Mitchell, B.G., Siegel, D.A., Carder, K.L., Garver, S.A., Kahru, M. and McClain, C. (1998), Ocean Color Chlorophyll Algorithms for SeaWiFS. Journal of Geophysical Research: Oceans, 103, 24937-24953. https://doi.org/10.1029/98JC02160

[19] O’Reilly, J.E., Maritorena, S., O’Brien, M.C., Siegel, D.A., Toole, D., Menzies, D., Smith, R.C., Mueller, J.L., Mitchell, B.G., Kahru, M., Chavez, F.P., Strutton, P., Cota, G.F., Hooker, S.B., McClain, C.R., Carder, K.L., Muller-Karger, F., Harding, L., Magnuson, A., Phinney, D., Moore, G.F., Aiken, J., Arrigo, K.R., Letelier, R. and Culver, M. (2000) SeaWiFS Postlaunch Calibration and Validation Analyses, Part 3. In: Hooker, S.B. and Firestone, E.R., Eds., SeWiFS Postlaunch Techincal Report Series, NASA Goddard Space Flight Center, Greenbelt, Vol. 11, 49.

[20] Sathyendranath, S. (2000) Remote Sensing of Ocean Colour in Coastal, and Other Optically-Complex, Waters. Reports of the International Ocean-Colour Coordinating Group, IOCCG, Dartmouth, Vol. 3.

[21] Barbini, R., Colao, F., Fantoni, R., Fiorani, L. and Palucci, A. (2003) Lidar Fluorosensor Calibration of the SeaWiFS Chlorophyll Algorithm in the Ross Sea. International Journal of Remote Sensing, 24, 3205-3218.

[22] Prieur, L. and Sathyendranath, S. (1981) An Optical Classification of Coastal and Oceanic Waters Based on the Specific Spectral Absorption Curves of Phytoplankton Pigments, Dissolved Organic-Matter, and Other Particulate Materials. Limnology and Oceanography, 26, 671-689. https://doi.org/10.4319/lo.1981.26.4.0671

[23] Lee, Z.P., Carder, K.L. and Arnone, R.A. (2002) Deriving Inherent Optical Properties from Water Color: A Multiband Quasi-Analytical Algorithm for Optically Deep Waters. Applied Optics, 41, 5755-5772. https://doi.org/10.1364/AO.41.005755

[24] Maritorena, S., Siegel, D.A. and Peterson, A.R. (2002) Optimization of a Semianalytical Ocean Color Model for Global-Scale Applications. Applied Optics, 41, 2705-2714. https://doi.org/10.1364/AO.41.002705

[25] Tilstone, G.H., Peters, S.W.M., van der Woerd, H.J., Eleveld, M.A., Ruddick, K., Schonfeld, W., Krasemann, H., Martinez-Vicente, V., Blondeau-Patissier, D., Rottgers, R., Sorensen, K., Jorgensen, P.V. and Shutler, J.D. (2012) Variability in Specific-Absorption Properties and Their Use in a Semi-Analytical Ocean Colour Algorithm for MERIS in North Sea and Western English Channel Coastal Waters. Remote Sensing of Environment, 118, 320-338. https://doi.org/10.1016/j.rse.2011.11.019

[26] Soppa, M.A., Dinter, T., Taylor, B.B. and Bracher, A. (2013) Satellite Derived Euphotic Depth in the Southern Ocean: Implications for Primary Production Modelling. Remote Sensing of Environment, 137, 198-211. https://doi.org/10.1016/j.rse.2013.06.017 
[27] Bierman, P., Lewis, M., Tanner, J. and Ostendorf, B. (2009) Remote Sensing-Validation, Spatial and Temporal Patterns in Sea Surface Temperature and Chlorophyll-a. SARDI, Adelaide, 287.

[28] Bierman, P.E. (2010) Remote Sensing to Monitor Interactions between Aquaculture and the Environment of Spencer Gulf, South Australia. PhD, The University of Adelaide, Adelaide.

[29] Carder, K.L., Chen, F.R., Lee, Z.P., Hawes, S.K. and Kamykowski, D. (1999) Semianalytic Moderate-Resolution Imaging Spectrometer Algorithms for Chlorophyll a and Absorption with Bio-Optical Domains Based on Nitrate-Depletion Temperatures. Journal of Geophysical Research-Oceans, 104, 5403-5421. https://doi.org/10.1029/1998JC900082

[30] Carder, K.L., Chen, F.R., Cannizzaro, J.P., Campbell, J.W. and Mitchell, B.G. (2004) Performance of the MODIS Semi-Analytical Ocean Color Algorithm for Chlorophyll-a. 1152-1159.

[31] Morel, A., Claustre, H., Antoine, D. and Gentili, B. (2007) Natural Variability of Bio-Optical Properties in Case 1 Waters: Attenuation and Reflectance within the Visible and Near-UV Spectral Domains, as Observed in South Pacific and Mediterranean Waters. Biogeosciences, 4, 913-925. https://doi.org/10.5194/bg-4-913-2007

[32] Middleton, J.F., James, N.P., James, C. and Bone, Y. (2014) Cross-Shelf Seawater Exchange Controls the Distribution of Temperature, Salinity, and Neritic Carbonate Sediments in the Great Australian Bight. Journal of Geophysical Research-Oceans, 119, 2539-2549. https://doi.org/10.1002/2013JC009420

[33] Kampf, J., Doubell, M., Griffin, D., Matthews, R.L. and Ward, T.M. (2004) Evidence of a Large Seasonal Coastal Upwelling System along the Southern Shelf of Australia. Geophysical Research Letters, 31, L09310. https://doi.org/10.1029/2003GL019221

[34] Cirano, M. and Middleton, J.F. (2004) Aspects of the Mean Wintertime Circulation along Australia's Southern Shelves: Numerical Studies. Journal of Physical Oceanography, 34, 668-684. https://doi.org/10.1175/2509.1

[35] Van Ruth, P.D., Ganf, G.G. and Ward, T.M. (2010) The Influence of Mixing on Primary Productivity: A Unique Application of Classical Critical Depth Theory. Progress in Oceanography, 85, 224-235. https://doi.org/10.1016/j.pocean.2010.03.002

[36] McClatchie, S., Middleton, J.F. and Ward, T.M. (2006) Water Mass Analysis and Alongshore Variation in Upwelling Intensity in the Eastern Great Australian Bight. Journal of Geophysical Research: Oceans, 111, C08007. https://doi.org/10.1029/2004JC002699

[37] Lewis, R. (1981) Seasonal Upwelling along the South-Eastern Coastline of South Australia. Marine and Freshwater Research, 32, 843-854.

https://doi.org/10.1071/MF9810843

[38] Lewis, R.K. (1982) A Statement to the Australian Marine Sciences and Technologies Advisory Committee on the South Australian Gulf System by the South Australian Department of Fisheries. In: Australian Marine Sciences and Technologies, Advisory Committee Seminar on the Research Needs for Management of the South Australian Gulfs, Gulfs, 53-58.

[39] Petrusevics, P.M. (1993) SST Fronts in Inverse Estuaries, South-Australia Indicators of Reduced Gulf Shelf Exchange. Australian Journal of Marine and Freshwater Research, 44, 305-323. https://doi.org/10.1071/MF9930305

[40] Ward, T.M., Burch, P., McLeay, L.J. and Ivey, A.R. (2011) Use of the Daily Egg Production Method for Stock Assessment of Sardine, Sardinops sagax, Lessons 
Learned over a Decade of Application off South Australia. Reviews in Fisheries Science, 19, 1-20. https://doi.org/10.1080/10641262.2010.528711

[41] Talling, J.F. and Driver (1963) Some Problems in the Estimation of Chlorophyll a in Phytoplankon. US Atomic Energy Committee, Washington DC.

[42] Baith, K., Lindsay, R., Fu, G. and McClain, C.R. (2001) Data Analysis System Developed for Ocean Color Satellite Sensors. Eos, Transactions American Geophysical Union, 82, 202. https://doi.org/10.1029/01EO00109

[43] Garver, S.A. and Siegel, D.A. (1997) Inherent Optical Property Inversion of Ocean Color Spectra and Its Biogeochemical Interpretation: 1. Time Series from the Sargasso Sea. Journal of Geophysical Research: Oceans, 102, 18607-18625. https://doi.org/10.1029/96JC03243

[44] Lee, Z., Weidemann, A., Kindle, J., Arnone, R., Carder, K.L. and Davis, C. (2007) Euphotic Zone Depth: Its Derivation and Implication to Ocean-Color Remote Sensing. Journal of Geophysical Research: Oceans, 112, C03009. https://doi.org/10.1029/2006JC003802

[45] McClain, C.R., Barnes, R.A., Eplee, R.E., Franz Jr., B.A., Hsu, N.C., Patt, F.S., Pietras, C.M., Robinson, W.D., Schieber, B.D., Schmidt, G.M., Wang, M., Bailey, S.W. and Werdell, P.J. (2000) SeaWiFS Postlaunch Calibration and Validation Analyses, Part 2. In: Hooker, S.B. and Firestone, E.R., Eds., SeaWIFS Postlaunch Technical Report Series, NASA Goddard Space Flight Center, Greenbelt, Vol. 10, 57.

[46] McClain, C.R., Feldman, G.C. and Hooker, S.B. (2004) An Overview of the SeaWIFS Project and Strategies of Producing a Climate Research Quality Global Ocean Bio-Optical Time Series. Deep Sea Research Part II: Topical Studies in Oceanography, 51, 5-42. https://doi.org/10.1016/j.dsr2.2003.11.001

[47] Hooker, S.B. and McClain, C.R. (2000) The Calibration and Validation of SeaWiFS Data. Progress in Oceanography, 45, 427-465. https://doi.org/10.1016/S0079-6611(00)00012-4

[48] Falkowski, P.G. and Kolber, Z. (1995) Variations in Chlorophyll Fluorescence Yields in Phytoplankton in the World Oceans. Australian Journal of Plant Physiology, 22, 341-355. https://doi.org/10.1071/PP9950341

[49] Babin, M., Morel, A. and Gentili, B. (1996) Remote Sensing of Sea Surface Sun-Induced Chlorophyll Fluorescence: Consequences of Natural Variations in the Optical Characteristics of Phytoplankton and the Quantum Yield of Chlorophyll a Fluorescence. International Journal of Remote Sensing, 17, 2417-2448. https://doi.org/10.1080/01431169608948781

[50] Babin, M. (2008) Phytoplankton Fluorescence: Theory, Current Literature and in Situ Measurement. In: Babin, M., Roesler, C.S. and Cullen, J.J., Eds., United Nations Educational, Scientific and Cultural Organization, Paris, 237-280.

[51] Krause, G.H. and Jahns, P. (2004) Non-Photochemical Energy Dissipation Determined by Chlorophyll Fluorescence Quenching: Characterization and Function. Springer, Berlin, 463-495.

[52] Dandonneau, Y. and Neveux, J. (1997) Diel Variations of in Vivo Fluorescence in the Eastern Equatorial Pacific: An Unvarying Pattern. Deep-Sea Research Part II Topical Studies in Oceanography, 44, 1869-1880. https://doi.org/10.1016/S0967-0645(97)00020-9

[53] Xing, X.G., Claustre, H., Blain, S., D’Ortenzio, F., Antoine, D., Ras, J. and Guinet, C. (2012) Quenching Correction for in Vivo Chlorophyll Fluorescence Acquired by Autonomous Platforms: A Case Study with Instrumented Elephant Seals in the Kerguelen Region (Southern Ocean). Limnology and Oceanography-Methods, 10, 
483-495. https://doi.org/10.4319/lom.2012.10.483

[54] Barton, I.J. (2007) Comparison of in Situ and Satellite-Derived Sea Surface Temperatures in the Gulf of Carpentaria. Journal of Atmospheric and Oceanic Technology, 24, 1773-1784. https://doi.org/10.1175/JTECH2084.1

[55] Chang, G.C. and Gould, R.W. (2006) Comparisons of Optical Properties of the Coastal Ocean Derived from Satellite Ocean Color and in Situ Measurements. Optics Express, 14, 10149-10163. https://doi.org/10.1364/OE.14.010149

[56] Guinet, C., Xing, X., Walker, E., Monestiez, P., Marchand, S., Picard, B., Jaud, T., Authier, M., Cotté, C., Dragon, A.C., Diamond, E., Antoine, D., Lovell, P., Blain, S., D'Ortenzio, F. and Claustre, H. (2013) Calibration Procedures and First Dataset of Southern Ocean Chlorophyll a Profiles Collected by Elephant Seals Equipped with a Newly Developed CTD-Fluorescence Tags. Earth System Science Data, 5, 15-29. https://doi.org/10.5194/essd-5-15-2013

[57] Doubell, M.J., Middleton, J.F., Spencer, D. and Lemckert, C.J. (2015) Salt-Finger Enhanced Mixing and Vertical Nutrient Fluxes on Australia's Southern Shelf. Continental Shelf Research.

[58] Kampel, M., Lorenzzetti, J.A., Bentz, C.M., Nunes, R.A., Paranhos, R., Rudorff, F.M. and Politano, A.T. (2009) Simultaneous Measurements of Chlorophyll Concentration by Lidar, Fluorometry, Above-Water Radiometry, and Ocean Color MODIS Images in the Southwestern Atlantic. Sensors, 9, 528-541.

https://doi.org/10.3390/s90100528 